\title{
Preparation of Graphene-Copper Nanocomposite for Electrochemical Determination of Cadmium Ions in Water
}

\author{
Chunjiang Liu ${ }^{1}$ and Changlu Qiao ${ }^{2 *}$ \\ ${ }^{1}$ School of economics and management, Chang'an University, Xi'an, Shanxi, 710000, P.R. China \\ ${ }^{2}$ School of Water Conservancy \& Architectural Engineering, Shihezi University, Shihezi, Xinjiang \\ 832003, P.R. China \\ E-mail: qiaochanglu@ 126.com
}

doi: $10.20964 / 2017.09 .12$

Received: 27 February 2017 / Accepted: 21 June 2017 / Published: 13 August 2017

Films of a graphene/copper composite in a copper matrix were deposited on ITO using an aqueous electrolyte solution containing $0.2 \mathrm{M} \mathrm{CuSO}_{4}$ and a graphene oxide suspension at a low current density. Using a further calefaction of the specimens under a flowing hydrogen atmosphere, graphene oxide was reduced. After this, the detection of cadmium(II) using square-wave voltammetry (SWV) on the $\mathrm{Cu}$-graphene/ITO film was illustrated. This approach utilized ion accumulation on the $\mathrm{Cu}$ graphene/ITO film. The performance of the Cu-graphene/ITO film was optimized by surface modification and changing the operating conditions.

Keywords: Graphene; Copper; Nanocomposite; Cadmium ions; Electrochemical sensor; Water

\section{FULL TEXT}

(C) 2017 The Authors. Published by ESG (www.electrochemsci.org). This article is an open access article distributed under the terms and conditions of the Creative Commons Attribution license (http://creativecommons.org/licenses/by/4.0/). 